\title{
Zinc oxide nanoparticle-induced atherosclerotic alterations in vitro and in vivo
}

\author{
This article was published in the following Dove Press journal: \\ International Journal of Nanomedicine \\ 13 June 2017 \\ Number of times this article has been viewed
}

\section{Zhen Yan ${ }^{1, *}$ \\ Wenjun Wang $2, *$ \\ Yongjun $\mathrm{Wu}^{1, *}$ \\ Wei Wang ${ }^{2}$ \\ Bing $\mathrm{Li}^{\prime}$ \\ Ning Liang' \\ Weidong $\mathrm{Wu}^{3}$}

'College of Public Health, Zhengzhou University, Zhengzhou, ${ }^{2}$ School of Public Health, Jining Medical University, Jining, ${ }^{3}$ School of Public Health, Xinxiang Medical University, Xinxiang, People's Republic of China

*These authors contributed equally to this work
Correspondence: Weidong Wu

School of Public Health, Xinxiang Medical

University, 60I Jinsui Avenue, Xinxiang,

Henan Province 453003, People's

Republic of China

Tel +86373383 I05।

Emailwdwu2013@126.com

\begin{abstract}
Engineered zinc oxide nanoparticles (ZnO-NPs) are currently being produced in high tonnage. Exposure to $\mathrm{ZnO}-\mathrm{NPs}$ presents potential risks to cardiovascular system. Thus far, the toxicological effects of ZnO-NPs on cardiovascular system have not been well characterized. In this study, human coronary artery endothelial cells (HCAECs) were exposed to ZnO-NPs directly or indirectly using a transwell coculture system with human alveolar epithelial cell line A549 to mimic the lung/circulation interaction. It was shown that levels of proinflammatory mediators (interleukin- 8 [IL-8] and tumor necrosis factor- $\alpha$ [TNF- $\alpha]$ ) and biomarkers of atherosclerogenesis (heme oxygenase-1 [HO-1] and platelet endothelial cell adhesion molecules-1 [PECAM-1]) in the supernatants of culture media were significantly increased. Pretreatment of A549 cells on the apical side of the coculture system with the phagocytosis inhibitor cytochalasin $\mathrm{B}$ (CB) blocked ZnO-NP-induced HO-1 and PECAM-1 expression in HCAEC, indicating that endocytosis of ZnO-NPs by alveolar epithelial cells was involved in ZnO-NP-induced HO-1 or PECAM-1 expression in endothelial cells. Moreover, Wistar rats were intratracheally instilled with $\mathrm{ZnO}-\mathrm{NP}$ suspension and high fat diet (positive control). ZnO-NP treatment induced lung and systemic inflammation, dyslipidemia, increased levels of serum HO-1 and PECAM-1, and aortic pathological damage. Taken together, exposure to ZnO-NPs could induce atherosclerotic alterations, which might involve phagocytosis of nanoparticles and inflammation in the lung.
\end{abstract}

Keywords: zinc oxide nanoparticles, atherosclerosis, lung inflammation, heme oxygenase-1, platelet endothelial cell adhesion molecules-1

\section{Introduction}

Zinc oxide $(\mathrm{ZnO})$ nanoparticles (NPs) are widely applied in various commercial and industrial products such as food additives, cosmetics, drug delivery, and personal hygiene products, which are due to their UV light absorption, antimicrobial, and catalytic properties, among others. ${ }^{1,2}$ There are multiple exposure pathways to $\mathrm{ZnO}-\mathrm{NPs}$, such as occupational exposure to $\mathrm{ZnO}-\mathrm{NPs}$ in manufacturing processes and environmental exposure to $\mathrm{ZnO}-\mathrm{NPs}$ from air pollution. ${ }^{3,4}$

Inhalation of NPs is associated with pulmonary and cardiovascular responses. ${ }^{5,6}$ Inhaled nanoparticles can readily deposit in lung tissue and induce inflammatory response in lung alveoli. ${ }^{7,8}$ Translocation of inhaled nanoparticles into the systemic circulation has been detected and might be related to adverse cardiovascular effects. It has been recently assumed that the main mechanism for translocation of inhaled nanoscaled particles appears to be via endocytosis of alveolar epithelial cells. ${ }^{9}$ Recently, much attention has been focused on the link between nanoparticles and cardiovascular diseases. Existing evidence suggests that exposure to ultrafine particulate matter is linked to increased incidence of cardiovascular diseases. ${ }^{10,11}$ Silica nanoparticles induce 
autophagic activity in vascular endothelial cells (ECs) and pericytes and subsequently disturb the EC homeostasis and impair angiogenesis. ${ }^{12}$ A recent animal study has shown that a single intratracheal administration of saline solution containing $\mathrm{TiO}_{2}$ nanoparticles increases cardiac conduction velocity and tissue excitability, resulting in an enhanced propensity for inducible arrhythmias. ${ }^{13}$ In addition, both multiwalled carbon nanotubes and $\mathrm{ZnO}-\mathrm{NPs}$ have been demonstrated to induce procoagulant effects. ${ }^{14}$ Thus, $\mathrm{ZnO}$-NPs are possible to cause harmful effects on cardiovascular system, ${ }^{15}$ yet the mechanisms underlying this correlation remain unclear.

In this present study, we aimed to characterize the cardiovascular effects induced by $\mathrm{ZnO}-\mathrm{NPs}$ in vitro and in vivo and possible mechanisms. In the in vitro study, human coronary artery endothelial cells (HCAECs) were exposed to ZnO-NPs in either monoculture or coculture with human alveolar type II epithelial cells (A549), then levels of interleukin-8 (IL-8), tumor necrosis factor- $\alpha$ (TNF- $\alpha$ ), heme oxygenase-1 (HO-1), and atherosclerotic biomarkers including platelet endothelial cell adhesion molecules-1 (PECAM-1) were determined. Through these studies, whether and how the lung was involved in $\mathrm{ZnO}$-NP-induced atherosclerotic alterations would be clarified. The animal study was designed to investigate the atherosclerotic disorders induced by intratracheally instilled $\mathrm{ZnO}-\mathrm{NPs}$.

\section{Materials and methods Preparation of $\mathrm{ZnO}$-NP suspension}

Uncoated $\mathrm{ZnO}-\mathrm{NPs}$ (30 $\mathrm{nm}$ in diameter) were purchased from Nanjing High Technology of Nano Co. (Nanjing, People's Republic of China) with the purity of $99.5 \%$. The characteristics of $\mathrm{ZnO}-\mathrm{NPs}$ were depicted previously. ${ }^{16}$ Stock suspension of $\mathrm{ZnO}-\mathrm{NPs}(1 \mathrm{mg} / \mathrm{mL})$ was prepared freshly in phosphate-buffered saline (PBS, $\mathrm{pH} 7.4$ ) and sonicated for $30 \mathrm{~s}$ prior to exposure.

\section{In vitro monoculture and coculture models}

HCAECs were obtained from Lonza Inc (Basel, Switzerland) and A549 cells from Type Culture Collection of Chinese Academy of Sciences (Shanghai, People's Republic of China). Cells were maintained in RPMI 1640 culture medium supplemented with $10 \%$ fetal bovine serum and $1 \%$ penicillin-streptomycin in a humidified atmosphere containing $5 \% \mathrm{CO}_{2}$ at $37^{\circ} \mathrm{C}$. Cells were passaged at $80 \%-90 \%$ confluency using trypsin-EDTA solution.

As for the coculture model, A549 cells were seeded into Transwell ${ }^{\circledR}$ inserts $\left(1.12 \mathrm{~cm}^{2}\right.$ for the 12 -well polycarbonate plate, pore size $0.4 \mu \mathrm{m}$ ) precoated with collagen I separating the well into an apical and a basal compartment, and HCAECs were seeded into the basal tissue culture plates with $0.5 \mathrm{~mL}$ medium in the upper compartment (insert) and $1 \mathrm{~mL}$ in lower compartment (Scheme 1).

\section{Cytotoxicity}

HCAEC and A549 cells were incubated with ZnO-NPs $(0,12.5,25,50,100$, and $200 \mu \mathrm{g} / \mathrm{mL})$ for $24 \mathrm{~h}$, respectively. Cytotoxicity of ZnO-NPs to A549 and HCAEC was evaluated by MTT assay. Cell viability was expressed as percentage of control as described previously. ${ }^{16}$

\section{Enzyme-linked immunosorbent assay (ELISA)}

Protein levels of IL-8, TNF- $\alpha$, HO-1, and PECAM-1 in the supernatants of culture media were measured with ELISA kits (Elabscience Biotechnology Co., Ltd., Cusabio, People's Republic of China) according to the manufacturer's recommendations. The experiment was performed in triplicate.

\section{Measurement of ZnO-NPs solubility}

The HCAEC in monoculture and coculture were collected and washed with PBS for five times after treatment of $\mathrm{ZnO}-\mathrm{NPs}$ with indicated concentration for $24 \mathrm{~h}$. The cells were disrupted by ultrasonication. The supernatant of cell lysate was collected and centrifuged at $13,000 \times g$ for $5 \mathrm{~min}$. $\mathrm{Zn}$ levels in the supernatant were measured with C2II2 atomic absorption spectrophotometer.

\section{Phagocytosis assay}

HECAE and A549 cells were cocultured on 12-well plate. A549 cells in coculture were preincubated with $10 \mu \mathrm{g} / \mathrm{mL}$ cytochalasin B (CB; EMD, San Diego, CA, USA) and vehicle control (DMSO; Sigma-Aldrich Co., St Louis, MO, USA) for $30 \mathrm{~min}$ prior to $\mathrm{ZnO}-\mathrm{NPs}(40 \mu \mathrm{g} / \mathrm{mL})$ treatment for another $24 \mathrm{~h}$. ZnO-NPs had the ability to interact with the epithelial barrier but did not appear to pass through the Transwell membrane to the endothelial layer. The supernatant in the basolateral chamber was harvested to measure the levels of HO-1 and PECAM-1 using ELISA.

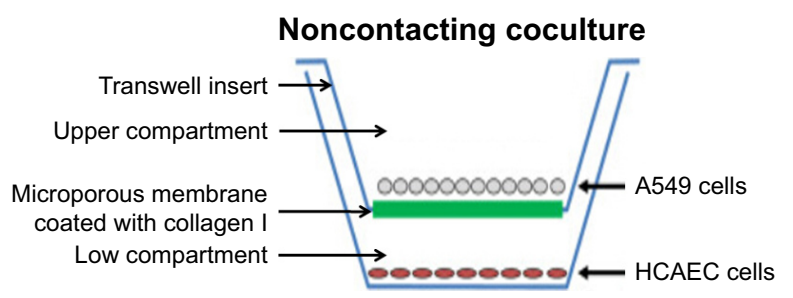

Scheme I Schematic diagram of noncontacting coculture of HCAEC and A549 cells. Abbreviations: HCAEC, human coronary artery endothelial cells; A549, human alveolar type II epithelial cells. 


\section{Animal treatment}

Male Wistar rats (body weight $180 \pm 10 \mathrm{~g}$ ) were obtained from the Experimental Animal Center of Henan Province, China, and housed in a climate-controlled room with a 12-h light/dark cycle, fed with ad libitum diet and distilled water. After 1-week acclimation, 50 rats were randomized into five groups ( $\mathrm{n}=10$ rats per group). Four experimental groups were, respectively, intratracheally instilled with ZnO-NPs suspension with different concentrations $(0,1.25,2.5$, and $5.0 \mathrm{mg} / \mathrm{kg}$ ) once a week for a total of 12 weeks and fed with normal diet. Meanwhile, the other group was instilled with PBS and raised with high fat diet containing 3\% cholesterol, $0.5 \%$ sodium cholate, $0.2 \%$ propylthiouracil, $5 \%$ lard, and $91.3 \%$ basic diet. Animals were weighed each week. At the termination of experiment, fasting blood and bronchoalveolar lavage fluid (BALF) were collected. Epididymal adipose tissues were carefully removed and weighed, and its ratio to body weight was calculated. ${ }^{17}$ Aortas were separated for pathological examination at gross and microscopic levels, respectively. All the experimental procedures conducted on animals were approved by the Animal Care and Use Committee of Zhengzhou University and performed in strict accordance with the Guide for the Care and Use of Laboratory Animals of Zhengzhou University.

\section{Measurement of total protein and lactate dehydrogenase (LDH) in BALF}

Total protein content in BALF, a marker for vascular permeability, ${ }^{18}$ was assessed using a bicinchoninic acid assay kit (Beyotime, Jiangsu, People's Republic of China) and expressed as $\mu \mathrm{g} / \mathrm{mL}$. LDH activity, a marker for cytotoxicity, was evaluated using an LDH assay kit (Beyotime) and expressed as unit per liter (U/L). Total protein and LDH activity in BALF were determined to evaluate the pulmonary inflammation.

\section{Measurement of proinflammatory and atherosclerotic proteins}

Blood was centrifuged at $1,500 \times \mathrm{g}$ for $10 \mathrm{~min}$ at $4^{\circ} \mathrm{C}$ and serum separated, aliquoted, and stored at $-80^{\circ} \mathrm{C}$ until analysis. Serum total cholesterol (TC), low-density lipoprotein (LDL), high-density lipoprotein (HDL), IL-8, TNF- $\alpha$, HO-1, and PECAM-1 were analyzed using ELISA kits (Elabscience Biotechnology Co., Ltd.) according to the manufacturer's protocol.

\section{Statistical analysis}

All statistical analysis was performed using Statistical package for the Social Sciences (version 21.0; SPSS, Inc., Chicago, IL, USA). Data were presented as mean $\pm \mathrm{SD}$, and one-way analysis of variance (ANOVA) followed by post hoc LSD test was used for multiple comparisons except that body weight data were analyzed by repeated measures one-way ANOVA. Statistical significance was considered at $P<0.05$.

\section{Results \\ Cytotoxicity of ZnO-NPs}

MTT assay has been widely used for detection of cytotoxicity induced by environmental toxicants. Herein, we used MTT assay to determine the injurious effect of ZnO-NPs on A549 and HCAEC. As shown in Figure 1A, ZnO-NP treatment induced a dose-dependent reduction of viability in both A549 and HCAEC. At the concentration of $100 \mu \mathrm{g} / \mathrm{mL}$ with the incubation time of $24 \mathrm{~h}, \mathrm{ZnO}-\mathrm{NP}$ exposure caused
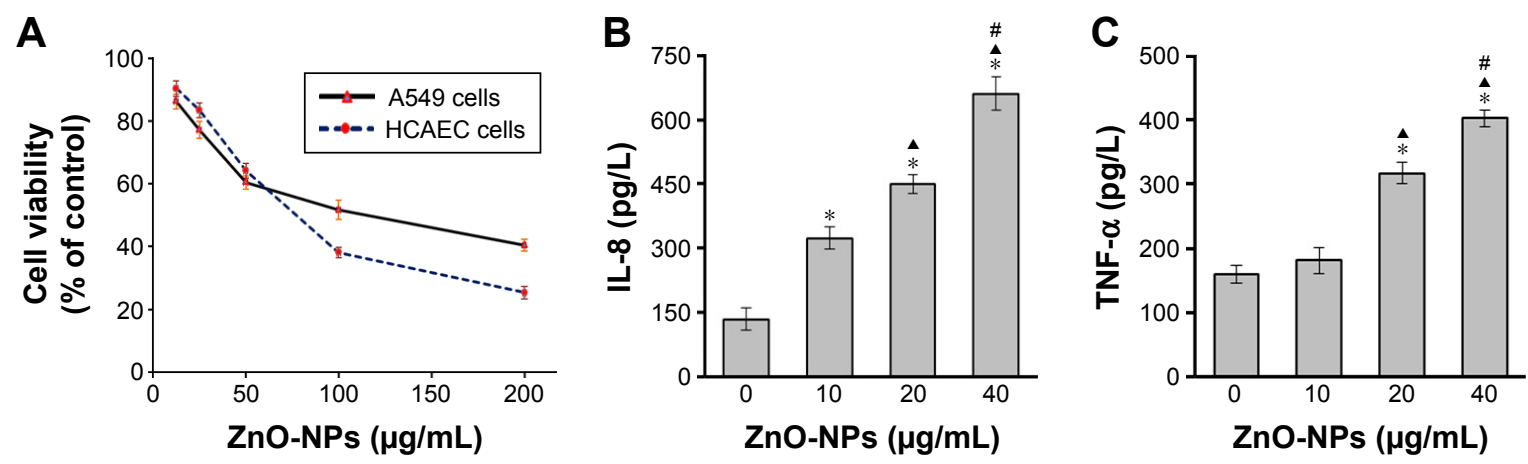

Figure I Effect of ZnO-NPs on cell viability and expression of IL-8 and TNF- $\alpha$ in coculture.

Notes: (A) HCAEC and A549 cells were incubated with ZnO-NPs, respectively. Cell viability was assessed by MTT assay. A549 cells in coculture were exposed to ZnO-NPs for $24 \mathrm{~h}$. The basolateral media were collected for analysis of IL-8 (B) and TNF- $\alpha(\mathbf{C})$ expression by ELISA. Data shown were representative of three separate experiments (*compared to control group, $P<0.05 ; \Delta$ compared to $10 \mu \mathrm{g} / \mathrm{mL}$ group, $P<0.05$; and "compared to $20 \mu \mathrm{g} / \mathrm{mL}$ group, $P<0.05$ ).

Abbreviations: ZnO-NPs, zinc oxide nanoparticles; IL-8, interleukin-8; TNF- $\alpha$, tumor necrosis factor- $\alpha$; HCAEC, human coronary artery endothelial cell; A549, human alveolar type II epithelial cells; MTT, 3-(4,5-dimethylthiazol-2-yl)-2,5-diphenyltetrazolium bromide; ELISA, enzyme-linked immunosorbent assay. 
about $50 \%$ of cell death in A549 cells. As for HCAEC, it was about $80 \mu \mathrm{g} / \mathrm{mL}$ when the cell viability was $50 \%$. These data indicated that $\mathrm{ZnO}-\mathrm{NPs}$ could markedly induce cell toxicity in both A549 and HCAEC.

\section{Exposure to $\mathrm{ZnO}-\mathrm{NPs}$ induced overexpression of IL-8 and TNF- $\alpha$ in coculture}

To examine the effect of $\mathrm{ZnO}-\mathrm{NPs}$ on inflammatory mediators in coculture, A549 cells in coculture system were exposed to $\mathrm{ZnO}-\mathrm{NPs}$ for $24 \mathrm{~h}$ and ELISA was used to measure IL- 8 and TNF- $\alpha$ protein levels. ZnO-NPs stimulation induced significant increases in both IL-8 (Figure 1B) and TNF- $\alpha$ (Figure 1C).

\section{Exposure to $\mathrm{ZnO}-\mathrm{NPs}$ induced $\mathrm{HO}-\mathrm{I}$ and PECAM-I overexpression of HCAEC in monoculture and coculture}

To determine the effect of ZnO-NPs on HO-1 and PECAM-1 expression in HCAEC, the monoculture and coculture system were exposed to $\mathrm{ZnO}-\mathrm{NPs}$ for $24 \mathrm{~h}$, and ELISA was used to measure the protein levels of HO-1 and PECAM-1 in HCAEC exposed to ZnO-NPs directly or indirectly. As shown in Figure 2, ZnO-NP direct stimulation induced a dose-dependent increase in both HO-1 and PECAM-1 expression in HCAEC monoculture. Similarly, the effect of $\mathrm{ZnO}-\mathrm{NPs}$ on coculture system also presented a dose-dependent increase in HO-1 and PECAM-1 protein release from HCAEC. As HO-1 and PECAM-1 protein levels increased in the basolateral chamber after ZnO-NPs exposure, it was assumed that cellular mediators secreted by A549 cells were capable of passing through the transwell membrane to the basolateral chamber, and further resulting in HO-1 and PECAM-1 expressions in HCAEC. Taken together, these results indicated that $\mathrm{ZnO}-\mathrm{NP}$ exposure upregulated $\mathrm{HO}-1$ and PECAM-1 expression in HCAECs with direct contact or indirect action through the mediators released from alveolar epithelial cells.

\section{Involvement of phagocytosis in ZnO-NP- induced $\mathrm{HO}-\mathrm{I}$ and PECAM-I expression of HCAEC in coculture}

Exposure to $\mathrm{ZnO}-\mathrm{NPs}$ could increase intracellular zinc levels of HCAEC in both monolayer and coculture models (Figure 3A), which suggested that $\mathrm{ZnO}-\mathrm{NPs}$ might be internalized and penetrated through the alveolar epithelial cells. $\mathrm{CB}$ could restrict the access of exogenous particles to cells through inhibiting phagocytosis. ${ }^{19}$ Exposure to ZnO-NPs induced significant expressions of HO-1 and PECAM-1 in HCAEC either in the presence or in the absence of A549 cells. Notably, pretreatment of A549 with CB modestly inhibited ZnO-NP-induced HO-1 (Figure 3B) and PECAM-1 (Figure 3C) expression in HCAEC. In combination, these results indicated that $\mathrm{ZnO}-\mathrm{NPs}$ could induce $\mathrm{HO}-1$ and PECAM-1 expression in HCAEC through the mediators released from A549 cells.

\section{$\mathrm{ZnO}-\mathrm{NP}$ treatment induced dyslipidemia in rats}

Rats in all experimental groups had similar initial body weight. Compared to that of the rats instilled with PBS, the body weight of rats instilled with $\mathrm{ZnO}-\mathrm{NPs}$ decreased from the fourth week (Figure 4A). Epididymal fat pads could be clearly isolated and often considered as the visceral fat.
A

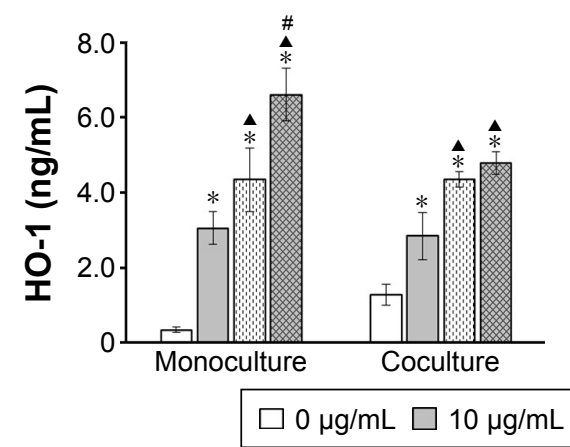

B

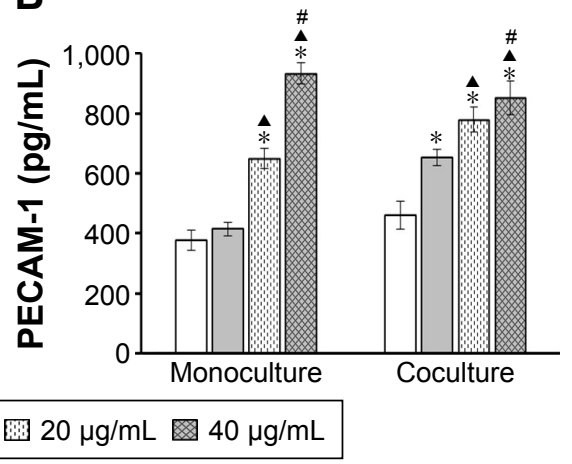

Figure 2 Effect of ZnO-NPs on HO-I and PECAM-I expression in HCAEC.

Notes: HCAECs were cultured in the presence (coculture) and in the absence (monoculture) of A549 cells on transwell membranes. HCAEC monoculture and A549 cells in coculture were incubated with ZnO-NPs for $24 \mathrm{~h}$, respectively. The expression of HO-I (A) and PECAM-I (B) from HCAEC in the supernatant was measured using ELISA (*compared to control group, $P<0.05 ; \mathbf{\Delta}$ compared to $10 \mu \mathrm{g} / \mathrm{mL}$ group, $P<0.05$; "compared to $20 \mu \mathrm{g} / \mathrm{mL}$ group, $P<0.05$ ).

Abbreviations: ZnO-NPs, zinc oxide nanoparticles; HO-I, heme oxygenase-I; PECAM-I, platelet endothelial cell adhesion molecule-I; HCAECs, human coronary artery endothelial cells; A549, human alveolar type II epithelial cells; ELISA, enzyme-linked immunosorbent assay. 


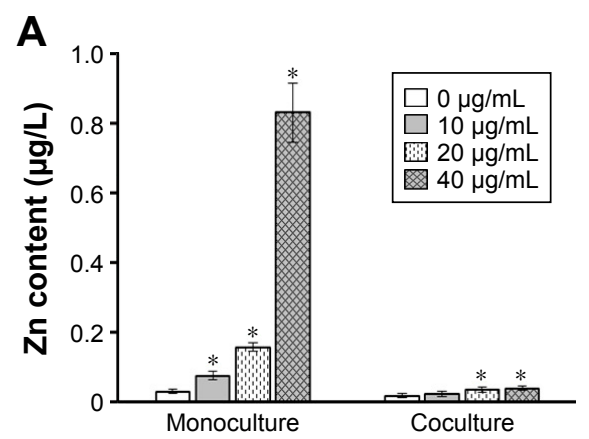

B

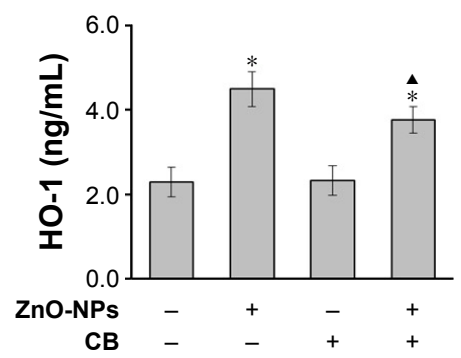

C

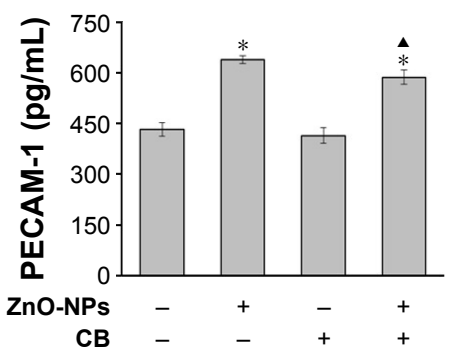

Figure 3 Effects of $\mathrm{CB}$ on ZnO-NP-induced HO-I and PECAM-I expression of HCAEC in coculture.

Notes: (A) HCAECs in monoculture and A549 cells in coculture were incubated with ZnO-NPs for 24 h. Levels of intracellular zinc contents in HEAEC were measured using flame atomic absorption spectrometry (*compared to control group, $P<0.05$ ). A549 cells in coculture were preincubated with $\mathrm{CB}$ or vehicle control, prior to ZnO-NP $(40 \mu \mathrm{g} / \mathrm{mL})$ treatment for $24 \mathrm{~h}$. HO-I (B) and PECAM-I (C) expression of the supernatant in basolateral chamber were measured using ELISA (*compared to the vehicle control group, $P<0.05 ; \Delta$ compared to $\mathrm{ZnO}$-NP-treated cells without $\mathrm{CB}$ treatment, $P<0.05)$.

Abbreviations: CB, cytochalasin B; ZnO-NPs, zinc oxide nanoparticles; HO-I, heme oxygenase-I; PECAM-I, platelet endothelial cell adhesion molecules-I; HCAEC, human coronary artery endothelial cells; A549, human alveolar type II epithelial cells; ELISA, enzyme-linked immunosorbent assay.

The ratio of epididymal fat pads vs body weight was calculated. As shown in Figure 4B, the ratios in high fat diet group and 2.5 or $5 \mathrm{mg} / \mathrm{kg} \mathrm{ZnO}-\mathrm{NPs}$ groups were all higher than that in PBS control group. The high fat diet group showed the highest ratio compared to other groups.
The effect of $\mathrm{ZnO}-\mathrm{NPs}$ on serum lipid profile of rats was demonstrated in Figure 4C-E, which showed a significant increase in TC and LDL levels in ZnO-NP-treated rats. However, HDL levels were remarkably decreased compared with those of control rats, which was similar to the change
A

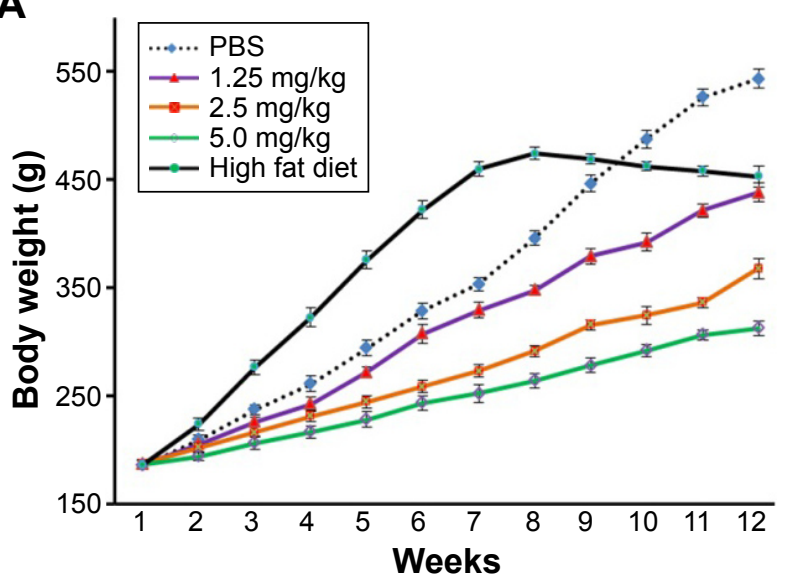

C

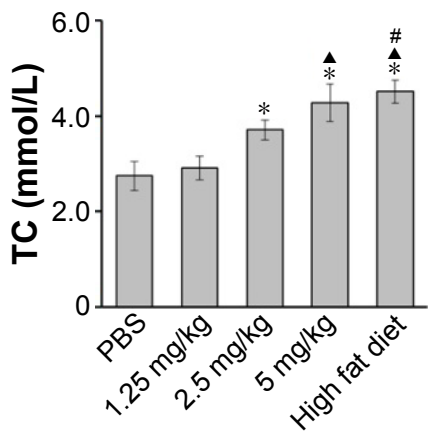

D

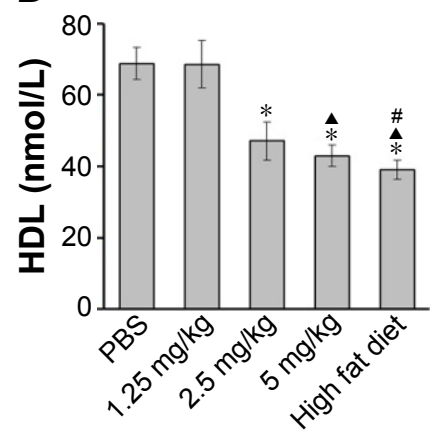

B

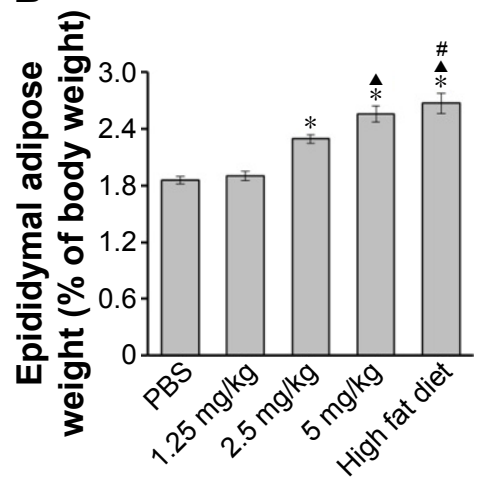

$\mathbf{E}$

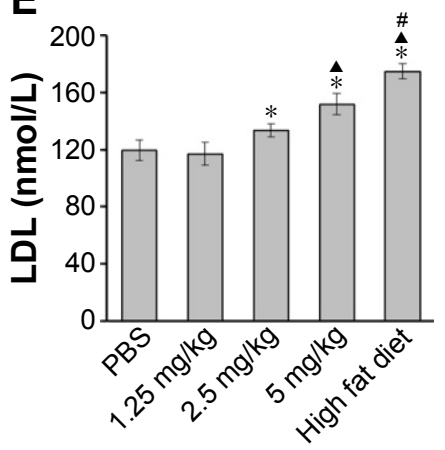

Figure $4 \mathrm{ZnO}$-NPs treatment induced dyslipidemia in rats.

Notes: (A) Body mass of rats was measured weekly during the experiment. After last instillation, rats were anesthetized and sacrificed. (B) Epididymal adipose tissue was removed and weighed, and its ratio to body weight was calculated. The blood samples collected from heart were tested for levels of serum TC (C), HDL (D), and LDL (E) using ELISA (*compared to control group, $P<0.05$; $\Delta$ compared to $2.5 \mathrm{mg} / \mathrm{kg}$ group, $P<0.05$; ${ }^{*}$ compared to $5 \mathrm{mg} / \mathrm{kg}$ group, $P<0.05$ ).

Abbreviations: ZnO-NPs, zinc oxide nanoparticles; TC, total cholesterol; HDL, high-density lipoprotein; LDL, low-density lipoprotein; ELISA, enzyme-linked immunosorbent assay. 
in high fat diet group. Taken together, these results showed that exposure to $\mathrm{ZnO}-\mathrm{NPs}$ could induce dyslipidemia, a premonitory alteration of atherosclerosis.

\section{Lung inflammation and systemic inflammation induced by $\mathrm{ZnO}$-NPs}

Protein contents (Figure 5A) in BALF from rats instilled with 2.5 or $5 \mathrm{mg} / \mathrm{kg} \mathrm{ZnO-NPs}$ were increased compared with that in control group. There were no difference among $1.25 \mathrm{mg} / \mathrm{kg}$ $\mathrm{ZnO}-\mathrm{NPs}$ group, high fat group, and control group. LDH activity (Figure 5B) in BALF of rats exposed to ZnO-NPs was increased in a dose-dependent manner and higher than those in control and high fat groups. Levels of serum IL-8
(Figure 5C) and TNF- $\alpha$ (Figure 5D) in rats exposed to $\mathrm{ZnO}-\mathrm{NPs}$ were both increased in a dose-dependent manner. TNF- $\alpha$ expression in high fat diet group was higher than that in PBS control group, but there was no significant difference between high fat diet group and PBS control group in the levels of serum IL-8.

\section{$\mathrm{ZnO}-\mathrm{NP}$-induced atherosclerotic alterations in rats}

HO-1 and PECAM-1 have been associated with atherosclerotic pathogenesis. ${ }^{20-22}$ Levels of serum $\mathrm{HO}-1$ (Figure 6A) and PECAM-1 (Figure 6B) in 2.5 and $5 \mathrm{mg} / \mathrm{kg} \mathrm{ZnO}-\mathrm{NPs}$ groups were higher than those in PBS control group. PECAM-1
A

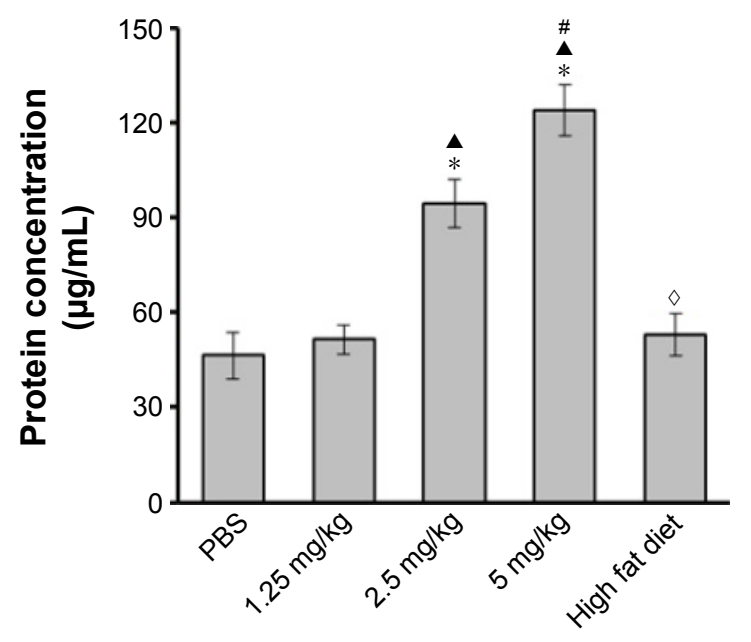

C

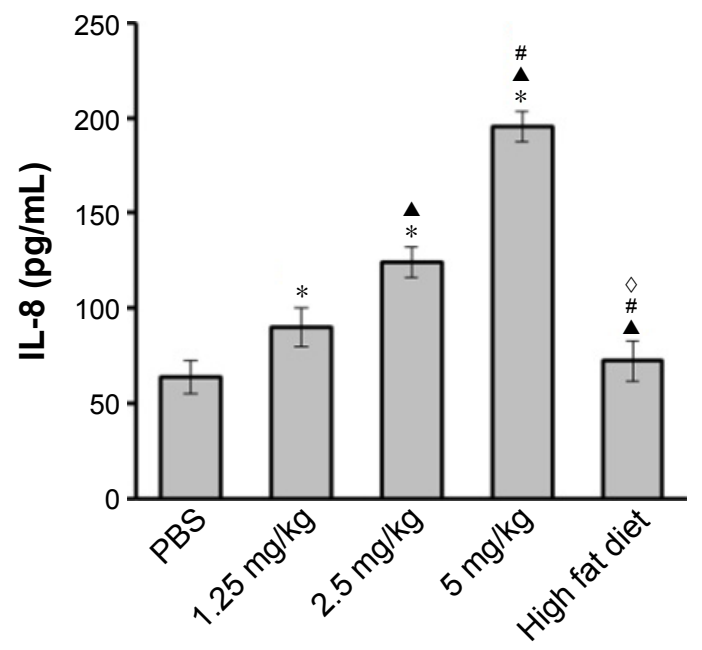

B

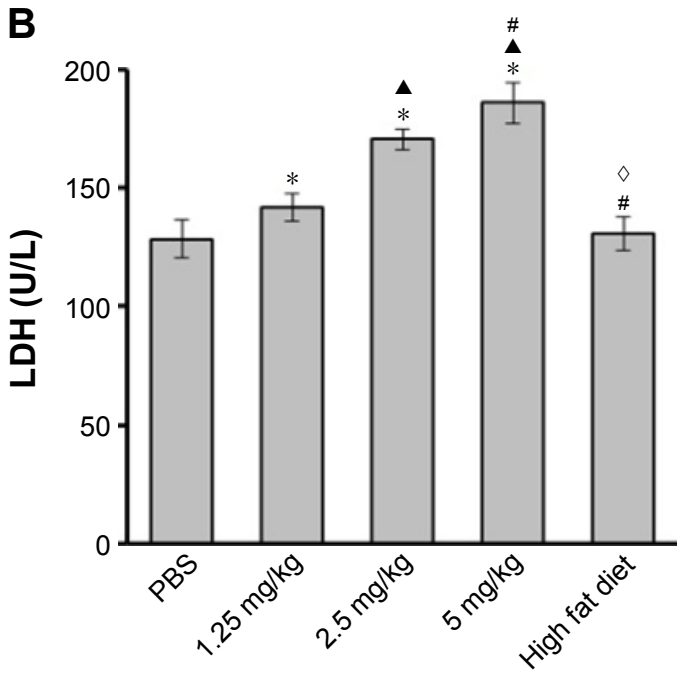

D

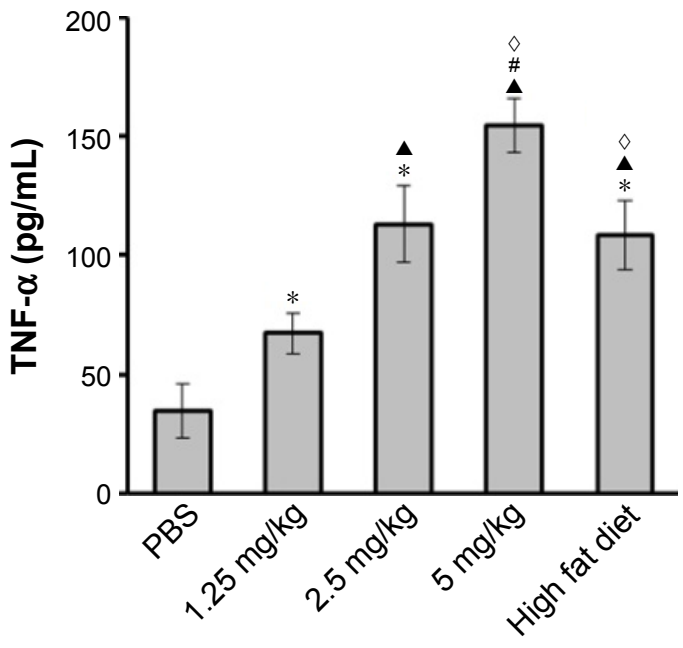

Figure $5 \mathrm{ZnO}-\mathrm{NP}$ induces lung inflammation and systemic inflammation.

Notes: After last instillation, rats were anesthetized and sacrificed. BALF was collected for the measurement of total proteins (A) and LDH (B) activity to represent the lung inflammation. The blood samples collected from heart were tested for levels of serum IL-8 (C) and TNF- $\alpha$ (D) using ELISA (*compared to control group, $P<0.05$; $\Delta$ compared to $1.25 \mathrm{mg} / \mathrm{kg}$ group, $P<0.05$; "compared to $2.5 \mathrm{mg} / \mathrm{kg}$ group, $P<0.05$; ${ }^{\circ}$ compared to $5 \mathrm{mg} / \mathrm{kg}$ group, $P<0.05$ ).

Abbreviations: ZnO-NPs, zinc oxide nanoparticles; BALF, bronchoalveolar lavage fluid; LDH, lactate dehydrogenase; IL-8, interleukin-8; TNF- $\alpha$, tumor necrosis factor- $\alpha$; ELISA, enzyme-linked immunosorbent assay. 


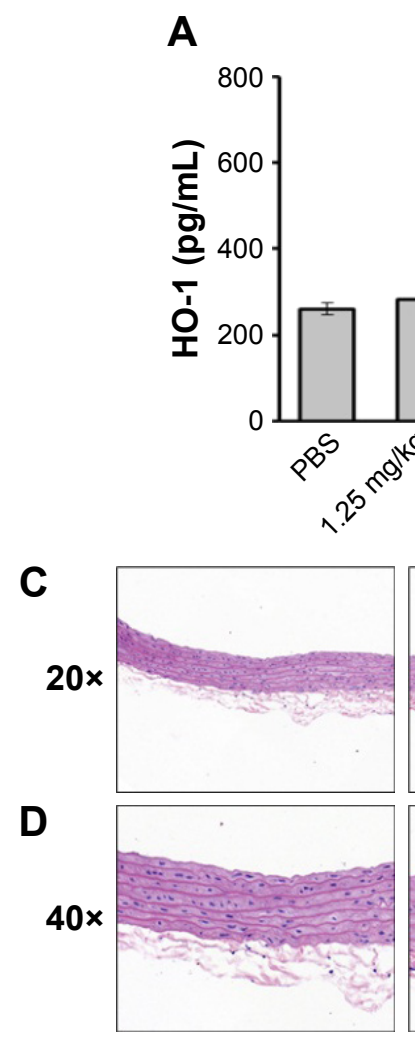

PBS

A
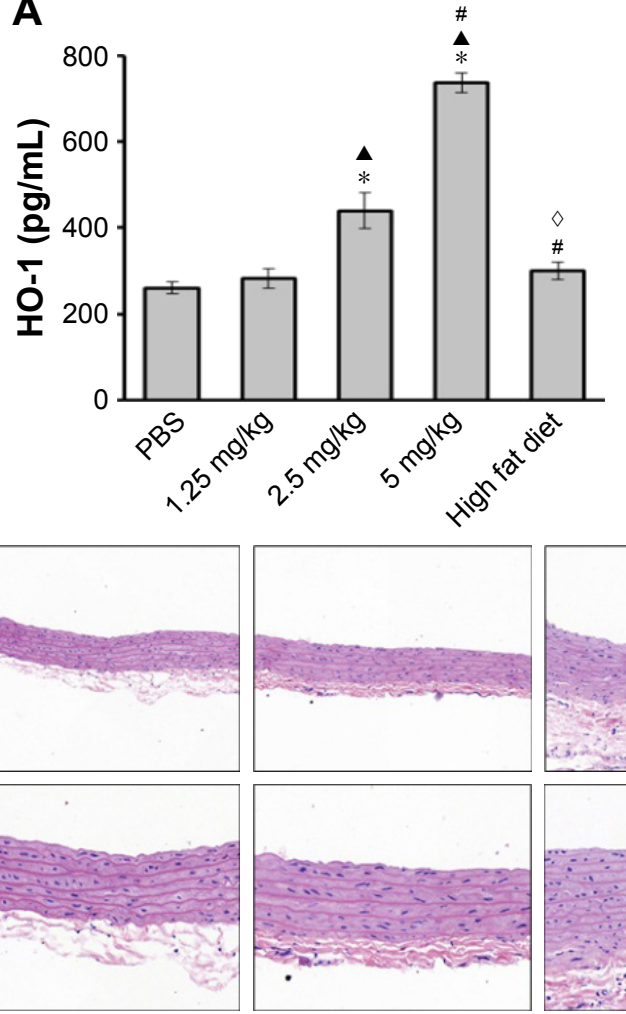

$1.25 \mathrm{mg} / \mathrm{kg}$

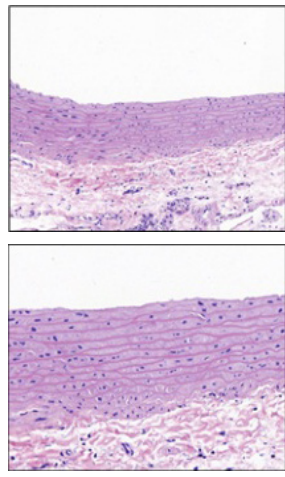

$2.5 \mathrm{mg} / \mathrm{kg}$
B

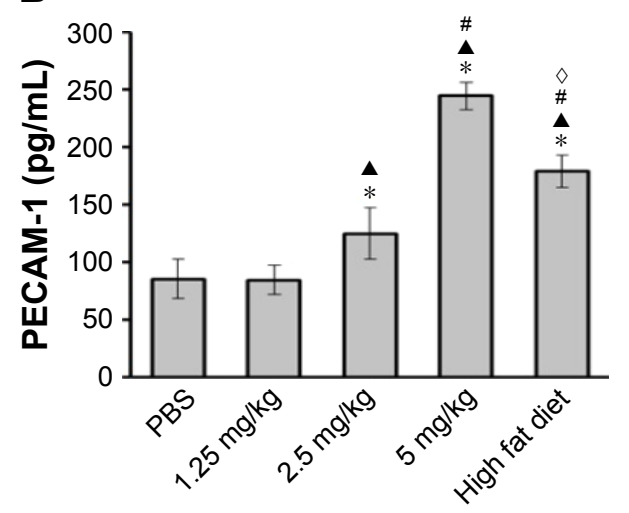

Figure $6 \mathrm{ZnO}-\mathrm{NP}$-induced atherosclerotic alterations in rats.

Notes: After last instillation, rats were anesthetized and the blood samples collected from heart were tested for levels of serum HO-I (A) and PECAM-I (B) using ELISA. The aortas were separated from the anesthetized rats. Light microscopy was used to analyze the aortic sections stained with $\mathrm{H} \& \mathrm{E}$ at gross (C, 20X) and microscopic (D, 40X)

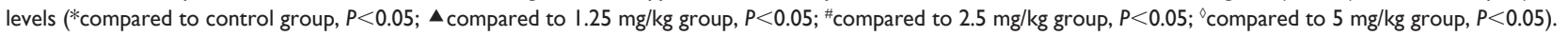
Abbreviations: ZnO-NPs, zinc oxide nanoparticles; HO-I, heme oxygenase-I; PECAM-I, platelet endothelial cell adhesion molecules-I; ELISA, enzyme-linked immunosorbent assay; H\&E, hematoxylin and eosin.

expression in high fat diet group was higher than that in PBS control group, but there was no significant difference between high fat diet group and PBS control group in levels of serum HO-1.

Histopathological examination of the aortic ECs in rats instilled with PBS using hematoxylin and eosin (H\&E) stain (Figure 6C and D) presented a complete continuous and smooth surface under light microscopy. In contrast, in the 1.25 and $2.5 \mathrm{mg} / \mathrm{kg} \mathrm{ZnO-NPs} \mathrm{groups,} \mathrm{the} \mathrm{arterial} \mathrm{intimal} \mathrm{sur-}$ face appeared smooth. However, the ECs were damaged and smooth muscle cell overgrowth to some extent. Remarkably, in the rats with high fat diet and $5 \mathrm{mg} / \mathrm{kg} \mathrm{ZnO}-\mathrm{NPs}$, thickened vessel wall, damaged smooth endometrial ECs, discontinued, or fragmented intimal surface were observed. Overgrowth and derangement of medial superficial smooth muscle cells were also observed, and subendothelial space was enlarged. Importantly, the medial smooth muscle cells were seen in the intima layer, indicative of their migration to the surface. In summary, $\mathrm{ZnO}-\mathrm{NP}$ exposure could induce atherosclerotic alterations in rats.

\section{Discussion}

A large number of studies have demonstrated that nanoparticles in the respiratory tract can cross the blood-air barrier, enter into bloodstream, and induce inflammation which is critical to the initiation of adverse pulmonary and cardiovascular reactions..$^{9,13,23}$ There are two main mechanisms to explain how pulmonary NPs exposure can initiate cardiovascular responses. One hypothesis states that NPs deposited in the lung elicit local inflammatory responses via oxidative stress that further develop into systemic oxidative stress/inflammation. ${ }^{24}$ On the other hand, NPs deposited in the lung can translocate into the systemic circulation and directly interact with cardiovascular tissues to induce injury or inflammation. ${ }^{25,26}$

ECs, which form the inner cellular lining of the entire cardiovascular system, have direct contact with NPs. ${ }^{27} \mathrm{ZnO}-\mathrm{NPs}$ direct stimulation could markedly induce cell toxicity and upregulate cardiovascular mediators, HO-1 and PECAM-1, in HCAEC. HO-1 is considered as an endogenous cytoprotective enzyme with an antioxidant role in cells including 
the ECs in response to various cellular stressors. ${ }^{28-30}$ Human and rodent experimental data also suggest that $\mathrm{HO}-1$ activity is antiatherogenic. ${ }^{29}$ PECAM-1, also called CD31, as a cell adhesion molecule, is mainly expressed on the surface of ECs, circulating platelets, monocytes, neutrophils, and certain T-cell subsets. PECAM-1 is thought to play a role in the pathological mechanisms of atherosclerosis..$^{22,31}$ Therefore, HO-1 and PECAM-1 were known to have a role in the pathogenesis of atherosclerosis. This study was also to determine whether the interaction of lung alveolar epithelial cells with $\mathrm{ZnO}-\mathrm{NPs}$ in vitro could affect the underlying vascular ECs. We examined nanoparticle indirect effects using an in vitro coculture model. Coculture is a promising alternative to monoculture and provides a more in vivo-like environment for the determination of toxicological results. ${ }^{32}$ In this system, levels of inflammatory cytokines, IL-8, and TNF- $\alpha$ were induced by $\mathrm{ZnO}-\mathrm{NPs}$ in a dose-dependent manner. Meanwhile, expression of HO-1 and PECAM-1 was increased significantly after $\mathrm{ZnO}-\mathrm{NPs}$ exposure in coculture model. Interestingly, differential background value of HO-1 expression was observed between monoculture and coculture cells, that is, HO-1 expression was very low in monoculture of HCAEC, but high in coculture, which is not consistent with the observation previous work showing that HO-1 expression and activity were only present in ECs from advanced atherosclerotic lesions. ${ }^{33}$ Although basal level of HO-1 protein in untreated HCAEC was typically low, a significant induction was seen following exposure to $\mathrm{ZnO}-\mathrm{NPs}$, and the change trend was in concert with the previous report, that is, atherosclerotic stimuli could upregulate the expression of HO- 1 .

$\mathrm{ZnO}-\mathrm{NPs}$ were previously shown to enter the lung epithelium in vivo and also be taken up by epithelial cells in vitro. ${ }^{16}$ Documented evidence has shown that NPs can be taken up by cells via well-known pathways of endocytosis. ${ }^{5}$ In order to explore the indirect effect of ZnO-NPs on ECs, $\mathrm{CB}$ was used to block the phagocytosis of nanoparticles. Pretreatment of A549 with CB could markedly suppress ZnONP-induced expressions of HO-1 and PECAM-1 in HCEAC in coculture. $\mathrm{CB}$ could decrease the access of $\mathrm{ZnO}-\mathrm{NP}$ to A549, which might release less cellular mediators so as to induce low HO-1 and PECAM-1 expressions in HCAEC. The results indicated that $\mathrm{ZnO}-\mathrm{NPs}$ could be internalized and penetrated through the alveolar epithelial cells and further induced HO-1 and PECAM-1 expressions. Taken together, the in vitro studies showed that $\mathrm{ZnO}-\mathrm{NPs}$ exposure induced the expression of inflammatory mediators and upregulated the regulators of atherosclerosis, such as HO-1 and PECAM-1, by means of endocytosis. This study also demonstrated that direct exposure of ECs to ZnO-NPs increased HO-1 and PECAM-1 expression in a dose-dependent manner. Therefore, it is envisioned that $\mathrm{ZnO}-\mathrm{NPs}$ could induce atherosclerotic alteration through direct contact with vascular ECs and indirect action through the released mediators from alveolar epithelial cells.

Pulmonary inflammation can further lead to systemic inflammation and various cardiovascular diseases. ${ }^{25}$ Therefore, the lung and systemic inflammatory responses may play a vital role in the pathological mechanisms of atherosclerosis and cerebral vascular disease. ${ }^{31}$ Based on the results from published studies, we hypothesized that $\mathrm{ZnO}$-NPs exert their inflammatory effects, which further drives the adverse cardiovascular effects. In this study, we investigated the atherosclerotic effect of $\mathrm{ZnO}-\mathrm{NPs}$ in vivo. High fat diet was thought to be a risk of cardiovascular diseases, ${ }^{34}$ therefore, the rats fed with high fat diet were served as the positive control. The present study demonstrated that ZnO-NPs exposure could influence the blood lipid by increasing TC, LDL, and visceral fat while lowering HDL, which indicated that $\mathrm{ZnO}$-NPs could potentially elevate the risk of atherosclerosis. Meanwhile, ZnO-NP exposure obviously elicited pulmonary and systemic inflammation and cardiovascular toxicity through increased HO-1 and PECAM-1. Finally, the cardiovascular toxicity of $\mathrm{ZnO}-\mathrm{NPs}$ was reflected as aortic morphological changes. Microscopic alterations in rats instilled with $\mathrm{ZnO}-\mathrm{NPs}$ ( $5 \mathrm{mg} / \mathrm{kg}$ ) were obvious, which were similar to the rats with high fat diet. However, it should also be noted that there was some difference between the effect of $\mathrm{ZnO}-\mathrm{NPs}$ and high fat diet, for example, high fat diet did not induce the increase in total protein, LDH, IL-8, and HO-1, except TNF- $\alpha$.

\section{Conclusion}

The current study has demonstrated that exposure to $\mathrm{ZnO}-\mathrm{NPs}$ could induce atherosclerotic alterations via direct and indirect actions. This process may involve oxidative stress, lipid metabolism disorders, and inflammation. Nanoparticle-induced pulmonary and systemic inflammation and accelerated atherosclerosis might be part of the pathophysiological pathways, linking nanoparticles with cardiovascular morbidity. Further research about endothelial dysfunction and mechanisms was needed to investigate the cardiovascular toxic effects of ZnO-NPs.

\section{Acknowledgments}

This project was supported by the grants from National Natural Science Foundation of China (81573112), Outstanding 
Young Talent Research Fund of Zhengzhou University (1521329034), and Basic and Frontier Technology Research Program of Henan Province (144300510055).

\section{Disclosure}

The authors report no conflicts of interest in this work.

\section{References}

1. Cho WS, Duffin R, Howie SE, et al. Progressive severe lung injury by zinc oxide nanoparticles; the role of $\mathrm{Zn} 2+$ dissolution inside lysosomes. Part Fibre Toxicol. 2011;8:27.

2. Chupani L, Zuskova E, Niksirat H, et al. Effects of chronic dietary exposure of zinc oxide nanoparticles on the serum protein profile of juvenile common carp (Cyprinus carpio L.). Sci Total Environ. 2017; 579:1504-1511.

3. Wu WD, Samet JM, Peden DB, Bromberg PA. Phosphorylation of p65 is required for zinc oxide nanoparticle-induced interleukin 8 expression in human bronchial epithelial cells. Environ Health Perspect. 2010;118(7):982-987.

4. Pan $\mathrm{CH}$, Chuang KJ, Chen JK, et al. Characterization of pulmonary protein profiles in response to zinc oxide nanoparticles in mice: a 24-hour and 28-day follow-up study. Int $J$ Nanomedicine. 2015;10: 4705-4716.

5. Muhlfeld C, Gehr P, Rothen-Rutishauser B. Translocation and cellular entering mechanisms of nanoparticles in the respiratory tract. Swiss Med Wkly. 2008;138(27-28):387-391.

6. McKinney W, Jackson M, Sager TM, et al. Pulmonary and cardiovascular responses of rats to inhalation of a commercial antimicrobial spray containing titanium dioxide nanoparticles. Inhal Toxicol. 2012; 24(7):447-457.

7. Song W, Wang JX, Liu ML, et al. Titanium dioxide nanoparticles induced proinflammation of primary cultured cardiac myocytes of rat. J Nanomater. 2014;13(43):7246-7254.

8. Warheit DB, Brock WJ, Lee KP, Webb TR, Reed KL. Comparative pulmonary toxicity inhalation and instillation studies with different $\mathrm{TiO} 2$ particle formulations: impact of surface treatments on particle toxicity. Toxicol Sci. 2005;88(2):514-524.

9. Elsaesser A, Howard CV. Toxicology of nanoparticles. Adv Drug Deliv Rev. 2012;64(2):129-137.

10. Peters A, Pope CA. Cardiopulmonary mortality and air pollution. Lancet. 2002;360(9341):1184-1185.

11. Oberdorster G, Oberdorster E, Oberdorster J. Nanotoxicology: an emerging discipline evolving from studies of ultrafine particles. Environ Health Perspect. 2005;113(7):823-839.

12. Duan J, Yu Y, Li Y, et al. Silica nanoparticles enhance autophagic activity, disturb endothelial cell homeostasis and impair angiogenesis. Part Fibre Toxicol. 2014;11(1):50.

13. Savi M, Rossi S, Bocchi L, et al. Titanium dioxide nanoparticles promote arrhythmias via a direct interaction with rat cardiac tissue. Part Fibre Toxicol. 2014;11(1):63.

14. Luyts K, Smulders S, Napierska D, et al. Pulmonary and hemostatic toxicity of multi-walled carbon nanotubes and zinc oxide nanoparticles after pulmonary exposure in Bmall knockout mice. Part Fibre Toxicol. 2014;11(1):61.

15. Li CH, Liao PL, Shyu MK, et al. Zinc oxide nanoparticles-induced intercellular adhesion molecule 1 expression requires $\mathrm{Rac} 1 / \mathrm{Cdc} 42$, mixed lineage kinase 3, and c-Jun N-terminal kinase activation in endothelial cells. Toxicol Sci. 2012;126(1):162-172.
16. Yan Z, Xu L, Han J, et al. Transcriptional and posttranscriptional regulation and endocytosis were involved in zinc oxide nanoparticleinduced interleukin-8 overexpression in human bronchial epithelial cells. Cell Biol Toxicol. 2014;30(2):79-88.

17. Cottrell EC, Martin-Gronert MS, Fernandez-Twinn DS, Luan J, Berends LM, Ozanne SE. Leptin-independent programming of adult body weight and adiposity in mice. Endocrinology. 2011;152(2):476-482.

18. Lee S, Hwang SH, Jeong J, et al. Nickel oxide nanoparticles can recruit eosinophils in the lungs of rats by the direct release of intracellular eotaxin. Part Fibre Toxicol. 2015;13(1):30.

19. Papageorgiou I, Brown C, Schins R, et al. The effect of nano- and micron-sized particles of cobalt-chromium alloy on human fibroblasts in vitro. Biomaterials. 2007;28(19):2946-2958.

20. Harry BL, Sanders JM, Feaver RE, et al. Endothelial cell PECAM-1 promotes atherosclerotic lesions in areas of disturbed flow in apoe-deficient mice. Arterioscler Thromb Vasc Biol. 2008;28(11):2003-2008.

21. Wang LJ,LeeTS,LeeFY, Pai RC, ChauLY.Expression of heme oxygenase-1 in atherosclerotic lesions. Am J Pathol. 1998;152(3):711-720.

22. Stevens HY, Melchior B, Bell KS, Yun SJ, Yeh JC, Frangos JA. PECAM-1 is a critical mediator of atherosclerosis. Dis Model Mech. 2008; $1(2-3): 175-181$.

23. Mossman BT, Borm PJ, Castranova V, Costa DL, Donaldson K, Kleeberger SR. Mechanisms of action of inhaled fibers, particles and nanoparticles in lung and cardiovascular diseases. Part Fibre Toxicol. 2007;4(1):1-10.

24. Lu X, Zhu T, Chen C, Liu Y. Right or left: the role of nanoparticles in pulmonary diseases. Int J Mol Sci. 2014;15(10):17577-17600.

25. Kang GS, Gillespie PA, Gunnison A, Moreira AL, Tchou-Wong KM, Chen LC. Long-term inhalation exposure to nickel nanoparticles exacerbated atherosclerosis in a susceptible mouse model. Environ Health Perspect. 2011;119(2):176-181.

26. Hoet PH, Bruske-Hohlfeld I, Salata OV. Nanoparticles - known and unknown health risks. J Nanobiotechnology. 2004;2(1):12.

27. Liu X, Sun J. Potential proinflammatory effects of hydroxyapatite nanoparticles on endothelial cells in a monocyte-endothelial cell coculture model. Int J Nanomedicine. 2014;9:1261-1273.

28. Yang G, Li Y, Wu W, et al. Anti-oxidant effect of heme oxygenase-1 on cigarette smoke-induced vascular injury. Mol Med Rep. 2015;12(2): 2481-2486.

29. Mylroie H, Dumont O, Bauer A, et al. PKCepsilon-CREB-Nrf2 signalling induces HO-1 in the vascular endothelium and enhances resistance to inflammation and apoptosis. Cardiovasc Res. 2015;106(3):509-519.

30. Pechlaner R, Willeit P, Summerer M, et al. Heme oxygenase-1 gene promoter microsatellite polymorphism is associated with progressive atherosclerosis and incident cardiovascular disease. Arterioscler Thromb Vasc Biol. 2015;35(1):229-236.

31. Song Y, Li Q, Long L, Zhang N, Liu Y. Asn563Ser polymorphism of CD31/PECAM-1 is associated with atherosclerotic cerebral infarction in a southern Han population. Neuropsychiatr Dis Treat. 2015;11: $15-20$.

32. Snyder-Talkington BN, Schwegler-Berry D, Castranova V, Qian Y, Guo NL. Multi-walled carbon nanotubes induce human microvascular endothelial cellular effects in an alveolar-capillary co-culture with small airway epithelial cells. Part Fibre Toxicol. 2013;10:35.

33. Morsi WG, Shaker OG, Ismail EF, et al. HO-1 and VGEF gene expression in human arteries with advanced atherosclerosis. Clin Biochem. 2006;39(11):1057-1062.

34. Attorri L, Di Biase A, Di Benedetto R, Rigato P, Di Virgilio A, Salvati S. Micronutrient-enriched rapeseed oils reduce cardiovascular disease risk factors in rats fed a high-fat diet. Atherosclerosis. 2010; 213(2):422-428. 


\section{Publish your work in this journal}

The International Journal of Nanomedicine is an international, peerreviewed journal focusing on the application of nanotechnology in diagnostics, therapeutics, and drug delivery systems throughout the biomedical field. This journal is indexed on PubMed Central,

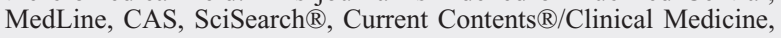

Journal Citation Reports/Science Edition, EMBase, Scopus and the Elsevier Bibliographic databases. The manuscript management system is completely online and includes a very quick and fair peer-review system, which is all easy to use. Visit http://www.dovepress.com/ testimonials.php to read real quotes from published authors.

Submit your manuscript here: http://www.dovepress.com/international-journal-of-nanomedicine-journal 